\title{
Plankton distributions and processes across a front in the open Baltic Sea
}

\author{
M. Kahru' ${ }^{1}$, J. Elken ${ }^{1}$, I. Kotta ${ }^{2}$, M. Simm ${ }^{2}$ and K. Vilbaste ${ }^{3}$ \\ ${ }^{1}$ Department of the Baltic Sea, Institute of Thermophysics and Electrophysics, Paldiski St. 1, Tallinn 200031, USSR \\ ${ }^{2}$ Tallinn Department of the Baltic Sea Fishery Research Institute, Apteegi St. 1, Tallinn 200001, USSR \\ ${ }^{3}$ Institute of Zoology and Botany, Vanemuise St. 21, Tartu 202400, USSR
}

\begin{abstract}
Sections of the temperature-salinity structure in the southeastern Gotland Basin, central Baltic Sea, revealed the existence of a pronounced salinity front. A water mass with anomalously low salinity extended vertically across the horizontally uniform thermocline. Plankton distribution and primary productivity showed consistent features with the frontal structure: the near-surface primary productivity increased 7 -fold adjacent to the front and levelled down farther away from it; the column chlorophyll had a broader and less distinct maximum on the high-salinity side of the front; the zooplankton community was similar in composition but its biomass more than doubled in the highersalinity water. It is suggested that upwelling of nutrient-rich water in the frontal zone had triggered the productivity peak, whereas the subsequent advection and diffusion were instrumental for the broader chlorophyll maximum. Owing to the lower phytoplankton/zooplankton ratio, the nutrient cycling had to be faster in the higher-salinity water mass.
\end{abstract}

\section{INTRODUCTION}

The existence of thermohaline fronts, i.e. boundaries between horizontally juxtaposed water masses, is probably a characteristic feature of the Baltic Sea. This has recently gained support from in situ CTD surveys (Aitsam et al., 1982b) as well as satellite imagery (Horstmann, 1983). The existence of fronts is to be expected as the brackish Baltic waters result from complicated mixing processes - lateral and vertical between water masses with different characteristics. Oceanic fronts are known to have important implications for biological productivity, distribution of pollutants, mixing, circulation, etc. (Bowman and Esaias, 1978). Due to the notorious difficulties in making highresolution measurements in the conceivably ubiquitous but relatively ephemeral and highly dynamic fronts in the Baltic Sea, there are only single observational studies, apart from scattered occasional observations.

From recent studies of the northwest European shelf (Floodgate et al., 1981; Holligan, 1981; Pingree et al., 1982), it has increasingly become apparent that fronts tidal, coastal, and shelf-break - are regions of elevated phytoplankton standing crop and biological productivity. The location of these fronts is controlled, among other factors, by the intensity of tidal stirring (Simpson and Hunter, 1974). Although the Baltic Sea fronts are evidently of different nature, they may have similar biological implications.

In 1980 we made a number of spatial chlorophyll/ CTD surveys of a stationary area in the central Baltic Sea, south-east from Gotland (Kahru et al., 1981, 1982). The striking mesoscale variability of the chlorophyll standing crop that was revealed was sometimes clearly associated with patterns in the thermohaline layering. This was interpreted as an indication of localized vertical fluxes of nutrients due to certain hydrographic features (shoaling of the halocline, narrowing of the intermediate layer). In 1981 in a near-by area we observed a synoptic-scale eddy carrying a cold and fresh water anomaly with a 2 to 3 -fold reduced chlorophyll a content (Aitsam et al., 1982a).

Here we report a series of measurements made in 1982 in the same area as in 1980, but including more biological detail. The space interval was reduced from 5 nautical miles (n.mi) to $2.5 \mathrm{n} . \mathrm{mi}$, thus providing better resolution and more confidence in the observed patterns. As the low-frequency variability of the Baltic Sea is to a great extent controlled by the bottom topography (Aitsam et al., 1983), we extended our observations across the whole trough, the locally dominant 
topographic feature. In order to assure reasonable synopticity, we had to confine the survey area to a transect instead of an areal polygon.

An extended period of calm and sunny weather preceding the survey was instrumental in creating an extraordinarily strong and uniform thermal stratification. It was therefore especially surprising to find a prominent salinity anomaly with a sharp frontal zone between the waters with different salinities. In conditions of extraordinarily uniform chlorophyll distribution there was a prominent primary productivity peak adjacent to the front.

\section{OBSERVATIONS AND METHODS}

The observations were made on RV 'Ayu-Dag' on Aug 6 to 7, 1982 along a $73-\mathrm{km}(40 \mathrm{n} . \mathrm{mi})$ long transect crossing a trough at the entrance to the Gotland Deep (Fig. 1). The direction of the transect was normal to the local isobaths. The position of the transect was chosen

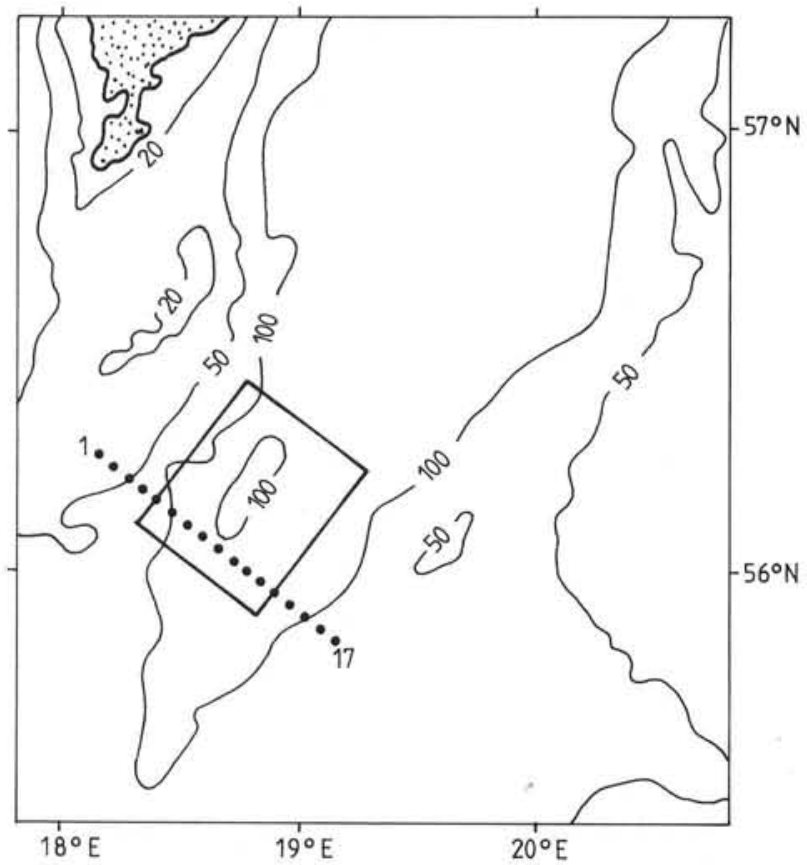

Fig. 1. Transect of stations and bathymetry of the area. Station spacing is 2.5 nautical miles. Solid rectangle is previous survey area of 1980

to cover a part of the 1980 area where the most conspicuous features had been observed (Fig. 5 in Kahru, 1982).

The transect with 17 stations was first covered from NW to SE (Section G) with a space interval of $2.5 \mathrm{n} . \mathrm{mi}$ $(4.6 \mathrm{~km})$ and a time interval of 40 to $50 \mathrm{~min}$ between stations. The stations are designated as G1 to G17. On the following day the stations with odd numbers were repeated in the reverse direction (Section $\mathrm{H}$ ). These stations, designated as $\mathrm{H} 17, \ldots, \mathrm{H} 1$, were thus separated by 5 n.mi. At each station, vertical profiles were taken with a profiler consisting of an NBIS Mark III conductivity-temperature-depth probe (Neil Brown Instrument Systems, Cataumet, USA) and an in situ Variosens fluorometer (Impulsphysik $\mathrm{GmbH}$, Hamburg, FRG). The fluorescence profile, with a vertical resolution of $\sim 18 \mathrm{~cm}$, was interpolated to a set of equispaced $(50 \mathrm{~cm})$ data points from 0.5 to $60 \mathrm{~m}$ depths. The methods of data acquisition and processing have been described earlier (Kahru et al., 1981).

Water sampling for chlorophyll extraction and onboard productivity measurements was done with a space interval of 5 n.mi (from odd numbered stations). Samples were collected from layers below (depth 30 to $35 \mathrm{~m})$, within (12 to $15 \mathrm{~m})$, and above ( 1 to $2 \mathrm{~m}$ ) the thermocline with a Niskin water sampler (General Oceanics, Miami, USA). As the samples were obtained after the in situ profiling, there is only a relative correspondence between in situ profiles and discrete samples. This is due to the ship's drift and the low vertical accuracy $(\sim 1 \mathrm{~m})$ of the bottle sampling. The extent of the discrepancy depends on the small-scale vertical and horizontal heterogeneity. Chlorophyll extraction and photometric analysis were made according to the recommendations by Edler (1979).

Rates of ${ }^{14} \mathrm{C}$ fixation by phytoplankton were estimated in an on-board incubator at saturating light intensity. The irradiance in the temperature controlled $\left(17^{\circ} \mathrm{C} \pm 1 \mathrm{C}^{\circ}\right)$ incubator bath was approximately $100 \mathrm{~W} \mathrm{~m}^{-2}$. Light from 'white' fluorescent tubes was used. The water samples from the near-surface and the thermocline layer were incubated for $2 \mathrm{~h}$. Dark fixation was measured only for the thermocline water and was assumed the same for the surface water. Millipore $0.45 \mu \mathrm{m}$ membrane filters and liquid scintillation counting (LKB RackBeta 1215, CPM values) were used. The $\mathrm{CO}_{2}$-content of the water was calculated from alkalinity titrations. Other details were according to Gargas (1975). Assimilation numbers were calculated relative to the chlorophyll concentration obtained photometrically from the same discrete water sample.

Samples for phytoplankton cell counts were obtained from 3 to 4 depths at G1, G13, and G17. Microscopic analysis was made on the sedimented samples from 11 of water preserved with Lugol's solution with acetic acid.

Zooplankton samples were collected with Juday kapron nets (mesh-size $0.09 \mathrm{~mm}$ ). At each station vertical hauls were made through the upper $10 \mathrm{~m}$ and through the whole water column from the bottom (or $70 \mathrm{~m})$. Samples were preserved with formaldehyde and analyzed by counting all the organisms. The biomasses were calculated on the basis of abundances and indi- 
vidual weights of different developmental stages of copepods and other organisms and are expressed as wet weight. Nutrient concentrations were, unfortunately, not measured although these could clarify some of the hypotheses made. The depth of the euphotic zone was assessed from the Secchi disc depth (Højerslev, 1982).

\section{RESULTS}

\section{Meteorology and hydrography}

For about 3 wk preceding the observations, the weather over the Baltic Sea was calm with highpressure areas dominating. Winds were weak, either from the north (19 to $30 \mathrm{Jul}$ ) or variable (1 to $6 \mathrm{Aug}$ ). Negligible wind, together with intense solar heating, caused an unusual warming of the surface water exceeding $22^{\circ} \mathrm{C}$ and a strong thermocline centered at about $14 \mathrm{~m}$.

Satellite infra-red imagery (Horstmann, 1983) shows that the weak northerly and easterly winds on 1 to 6 Aug were sufficient to induce Ekman upwelling along the Baltic east-coast. A band of cool upwelled water was seen to broaden gradually and drift westward in the form of irregular bands. It is uncertain, however, whether this water had reached the survey area by the time of observations. In the central Baltic Sea, the infra-red images show insufficient contrast.

The general density structure and the bottom contour across the trough is shown in Fig. 2. The density

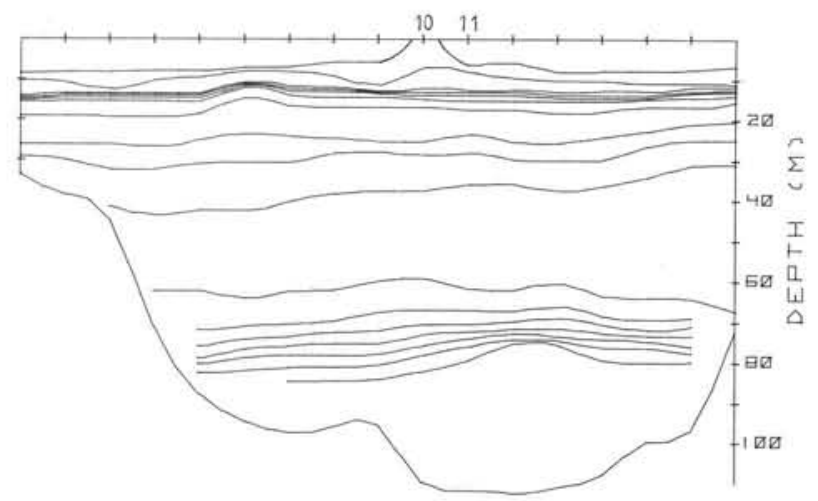

Fig. 2. Bottom contour across the trough and vertical density Section G on August 6, 1982. Contour interval is $0.25 \sigma_{t}$ units from 4.00 to 8.00 . The salinity front was situated between Stations 10 and 11

section shows a relatively deep $(\sim 70 \mathrm{~m})$ halocline and a particularly strong thermocline $(\sim 14 \mathrm{~m})$. Apart from the lifting of a few near-surface isopycnals at G10, the horizontal density structure looks particularly uniform. The density above the halocline is predominantly controlled by temperature, as can be seen from the contour plots (Fig. 2 and 3A). The salinity section (Fig. 3B) reveals a salinity front situated near the center of the transect. A water mass with anomalously low salinity extended vertically across the thermocline. Its core, a 5 -m thick wedge with the lowest salinity $(<7.50 \%)$, was centered in the thermocline $(\sim 15 \mathrm{~m})$ and extended horizontally for at least $40 \mathrm{~km}$ (Stations 1 to 10). The salinity front was nearly vertical in the depth range of 15 to $30 \mathrm{~m}$, but became inclined near the surface and near the bottom. The extension of the anomaly across the uniform thermocline suggests that the thermal structure had mainly formed after the different water masses came into contact. The salinity structure was especially rich in small-scale details which were below the spatial resolution of the station spacing. As on the following day the backward section $\mathrm{H}$ had the space interval increased from 2.5 to $5 \mathrm{n} . \mathrm{mi}$, the corresponding contour plots (not shown) lack some of the relevant details. Apart from further heating of the surface layer and a slight thickening of the lowsalinity wedge, only insignificant changes could be established between sections $\mathrm{G}$ and $\mathrm{H}$. Thus, the general frontal structure remained stationary for a period of at least for $1 \mathrm{~d}$.

Due to the primary productivity peak at G11 it is tempting to guess the origin of the uplift of the nearsurface isopycnals at G10 adjacent to the salinity discontinuity. It is known from the literature (e.g. Tang, 1982) that frontal zones are sites of upwelling due to the complicated circulation in fronts. A close examination of the density structure shows that the outcropping or lifting involves the isopycnals between $\sigma_{\mathrm{t}}=3.85$ and 4.50 in the depth range of 0 to $13 \mathrm{~m}$. Temporary distortion of isopycnal depths (lifting and sinking) may be caused by internal waves. Internal wave effects will be removed and the distorted contours should become horizontal if density, instead of depth, is used as the ordinate. This presentation (Fig. 3C) shows a distinct discontinuity in the $\sigma_{t}$ range 4.3 to 4.5 between Stations 9 and 10. It becomes evident that the front was manifested deeper than $60 \mathrm{~m}\left(\sigma_{t} \sim 6.5\right)$, which is not so obvious on other plots. A temporary effect of an internal wave can also be ruled out by the use of Section $\mathrm{H}$ data: it is highly improbable that in about $17 \mathrm{~h}$ similar disturbances were present on both sides of St. 10 (e.g. the significant sinking of the near-surface isopycnals at St. 9). In the upper part of the disturbance (isotherms 20 to $21^{\circ} \mathrm{C}$ and $\sigma_{t} \sim 4.0$ ) the contours do look nearly horizontal in Fig. 3C. This could indicate local upwelling due to the complicated dynamics in the frontal zone. Hence, although no definite conclusion is possible, we suggest, nevertheless, that the near-surface feature at St. 10 was not a fortuitous effect of an internal wave or diurnal heating cycle, but a signature of upwelling and, maybe, mixing in the frontal zone. 

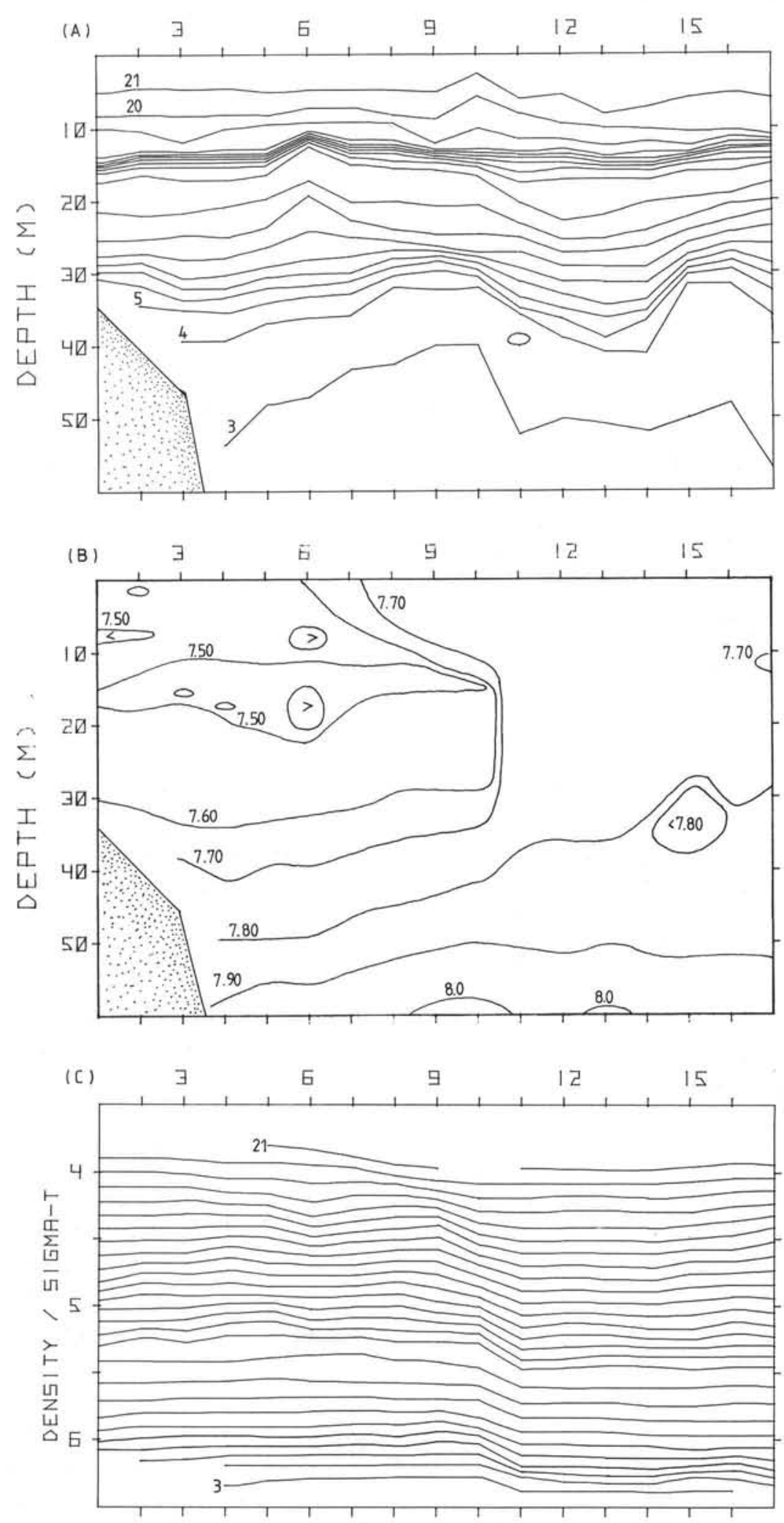

Fig. 3. Vertical sections of upper $60 \mathrm{~m}$ water column. (A) Temperature vs. depth. Contour interval is $1 \mathrm{C}^{\circ}$ from 21 to $3^{\circ} \mathrm{C}$. (B) Salinity vs. depth. Contour interval is $0.1 \%$ from 7.5 to $8.0 \%$. (C) Temperature vs. density $\left(\sigma_{t}\right)$. Contour intervals are $0.5 \mathrm{C}^{\circ}$ (from 21 to $13^{\circ} \mathrm{C}$ ) and $1 \mathrm{C}^{\circ}$ (from 13 to $3^{\circ} \mathrm{C}$ ) 
Apart from the low-salinity anomaly even the salinity on the higher-salinity side of the section was far below the mean salinity for this region. Compared to our 9 previous CTD/chlorophyll surveys in this area (Kahru and Aitsam, 1984), the salinities in the depth range 30 to $60 \mathrm{~m}$ were 0.3 to $0.5 \%$ lower than on other surveys during the same season. The origin of this climatic-scale variability is not clear. As a consequence of both the reduced salinity above the halocline and the deepness of the halocline, the depths of some of the isopycnals were drastically increased. For example, compared to survey 19/1 in July, 1980, the isopycnal $\sigma_{\mathrm{t}}=6.5$ was lowered by $\sim 30 \mathrm{~m}$ (from 35 to $65 \mathrm{~m}$ ). We believe that the high horizontal uniformity of temperature, the reduced salinity above the halocline, and the deepness of the isopycnals were all caused to some extent by the reduction of wind mixing and by the increased thermal stratification.

\section{Chlorophyll a}

The in situ fluorescence traces were calibrated against the extracted chlorophyll a measurements of discrete water samples (Kahru and Aitsam, 1984). The below-thermocline ( 30 to $35 \mathrm{~m}$ ) samples, seemingly forming a separate cluster, were treated separately. For the near-surface and thermocline samples the correlation is nearly perfect (Fig. $4 \mathrm{~A}$ ). It is not clear whether the thermocline samples from G15 and G17, lying off from the regression line, manifest real differences in the fluorescence intensity per unit chlorophyll $a$ or are due to a sensitivity loss of the fluorometer. The scatter of the below-thermocline samples from the aphotic zone is bigger and the slope is significantly higher (Fig. 4 B). However, as the intercepts are different too, a straightforward explanation is not possible. For the range of the deep samples observed, the specific fluorescence is higher than for other samples. Regardless of the causes for differences in the regression lines, the empirical procedure of using separate equations in different depth ranges ( 0 to $30 \mathrm{~m}$ vs. 30 to $60 \mathrm{~m}$ ) seems to yield rather accurate results. The resulting profiles, together with some salinity profiles, are shown in Fig. 5. Sharp subsurface chlorophyll maxima (up to $4 \mathrm{mg} \mathrm{m}^{-3}$ ) existed in the thermocline where the salinity stratification was strong (low-salinity side), whereas a relatively uniform vertical distribution was present in the higher-salinity water with a poor salinity stratification in the upper layers. Surprisingly, it appears that the vertical chlorophyll distribution was influenced not only by the density stratification (controlled primarily by temperature) but also by the salinity stratification. Vertical chlorophyll maxima were consistently confined either to the low-salinity wedge or to other smaller-scale, low-salinity intrusions.
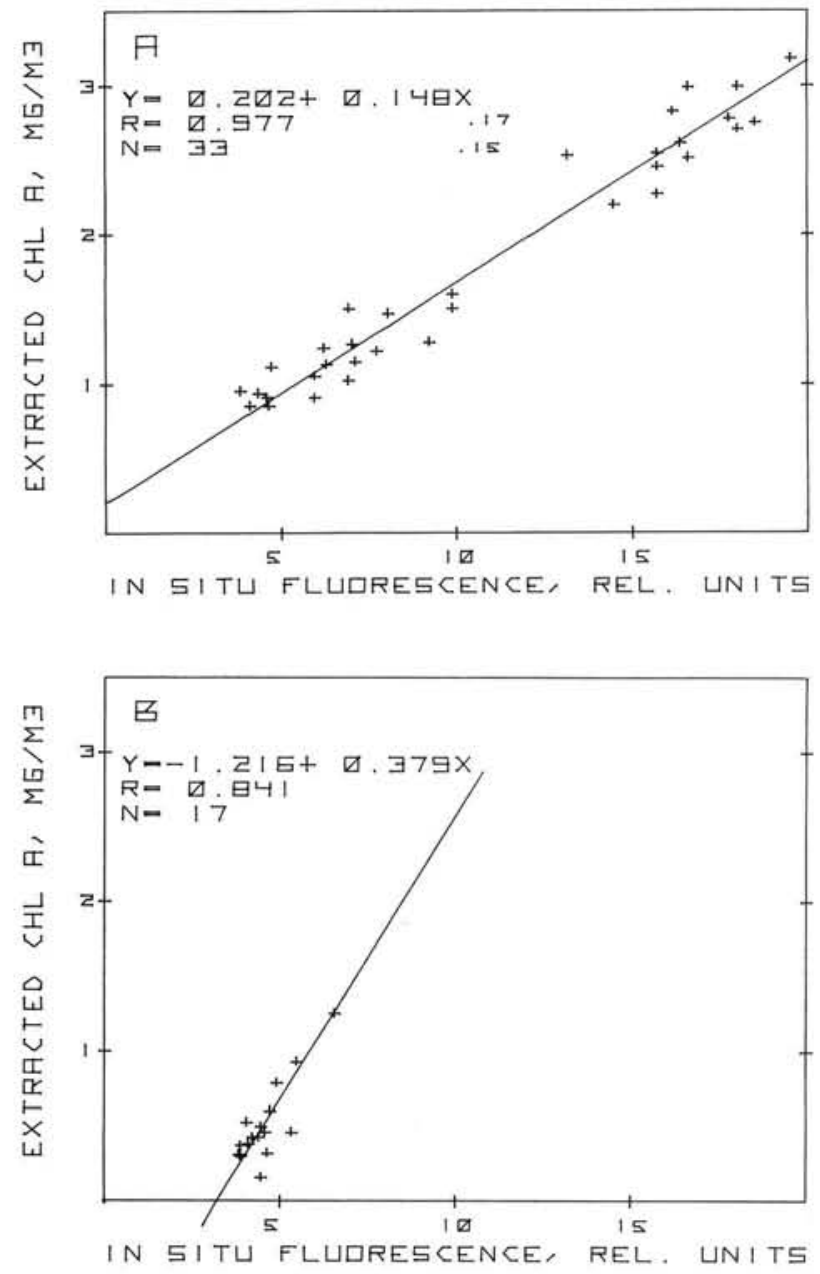

Fig. 4. Geometric mean regressions between extracted chlorophyll $a$ from discrete samples and in situ fluorescence. (A) Samples from thermocline (upper cluster) and surface layer (lower cluster). Thermocline samples from G15 and G17 were excluded from calculation. (B) Samples from belowthermocline layer. The correlation coefficients (R) and sample sizes $(\mathrm{N})$ indicated

As the vertical chlorophyll a profiles abound in small-scale structures, vertical integration of the concentration allows one to retain the most relevant mesoscale information (Kahru et al., 1981). The small-scale variability is further reduced if Sections $\mathrm{G}$ and $\mathrm{H}$ are pooled to yield mean values for the odd numbered stations. The integrated concentration for the upper $60 \mathrm{~m}$ approximates the total water column chlorophyll as the deeper layers add very little to this value. The distributions of the integrated chlorophyll a concentrations are shown in Fig. 6B with the positions of the salinity front and the near-surface increase in density shown for reference (Fig. 6A). A very noticeable feature is the exceptionally uniform distribution of the integrated chlorophyll. The coefficients of variation (C.V.) of the column ( 0 to $60 \mathrm{~m}$ ) chlorophyll on sections 

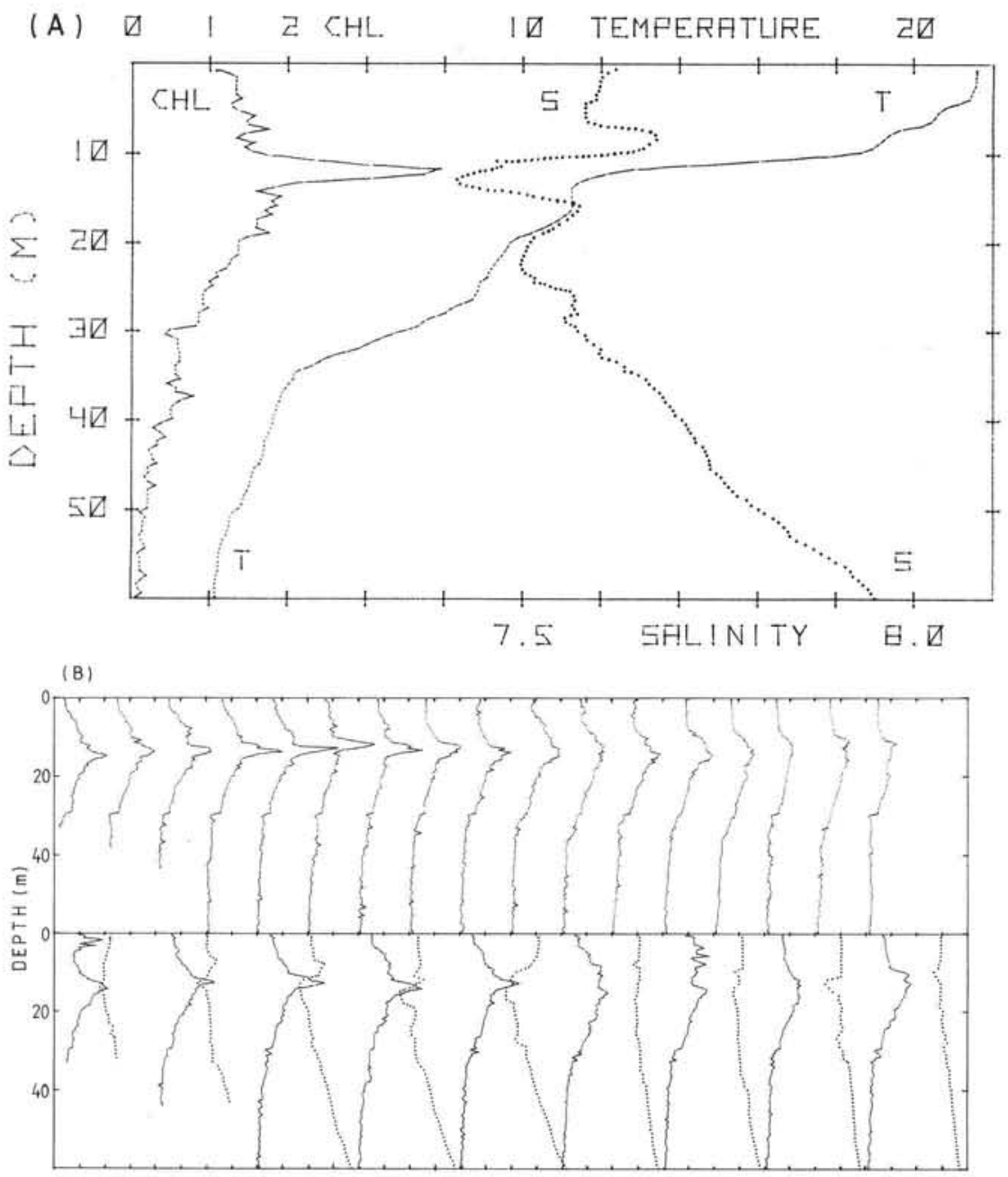

Fig. 5. Vertical profiles through upper 60-m layer. (A) Typical vertical structure, Station G6: chlorophyll a (CHL, mg $\left.\mathrm{m}^{-3}\right)$, temperature $\left({ }^{\circ} \mathrm{C}\right)$, salinity $(\%$, dotted line). (B) Series of chlorophyll a (solid curves) and salinity (dotted curves, Section $\mathrm{H}$ only) profiles of Sections $\mathrm{G}$ (upper panel) and $\mathrm{H}$ (lower panel). Station spacing is $2.5 \mathrm{n} . \mathrm{mi}$ (upper panel) or $5 \mathrm{n} . \mathrm{mi}$ (lower panel). Horizontal axis starts from $0.0 \mathrm{mg} \mathrm{m}^{-3}$ and $7.0 \%$, the units are $1.5 \mathrm{mg} \mathrm{m}^{-3}$ and $0.5 \%$. Each ensuing profile is offset $3.0 \mathrm{mg} \mathrm{m}^{-3}$ (upper panel), $6.0 \mathrm{mg} \mathrm{m}^{-3}$ and $1.0 \%$ (lower panel)

$\mathrm{G}$ and $\mathrm{H}, 13.1 \%$ and $7.8 \%$, respectively, rank the lowest among all the 16 meso-scale chlorophyll surveys made so far (the mean C.V. is $24.7 \%$ ). For the upper 30-m chlorophyll, the values of C.V., $16.3 \%$ and $9.0 \%$, rank respectively fourth and first (the mean C.V. is $26.7 \%$ ). It can only be speculated that the meteorological calmness and the extremely uniform temperature structure were influential in smoothing out a significant portion of the meso-scale chlorophyll variability.

When the average values for the low- and highsalinity water masses are compared (Table 1), regarding St. 10 as the frontal zone, it is apparent that, whereas the column chlorophyll values $(0$ to $30 \mathrm{~m}$ and 0 to $60 \mathrm{~m}$ ) were similar, deeper layers had a significantly higher chlorophyll a content in the higher-salinity water, but the thermocline values tended to be higher in the low-salinity water. Apart from the uniformity of the distribution, a broad and relatively smooth band $(\sim 20 \mathrm{~km})$ of increased column chlorophyll can be associated with the higher-salinity side of the front, and a slight increase in the upper 10- m chlorophyll may well be related to the near-surface density anomaly at G10 (Fig. 6B). These relatively moderate features, which might have remained unnoticed in case of the usual variability, acquire significance due to the upsurge of primary productivity at G11. The euphotic zone depths ranged from 12 to $16.5 \mathrm{~m}$ but the estimates were not considered sufficiently accurate to use them in any calculations. The deep chlorophyll maxima were found near the estimated bottom of the euphotic zone.

\section{Primary productivity}

As the phytoplankton ${ }^{14} \mathrm{C}$ fixation rate under nonlimited light conditions (potential primary production) was measured at every second station of Section G, the spatial resolution was, of course, lower compared to the chlorophyll data or to the hydrography. Nevertheless, spectacular patterns were evident in the distributions of both productivities and assimilation numbers (Fig. 6C, D). The near-surface productivities and 
(A)

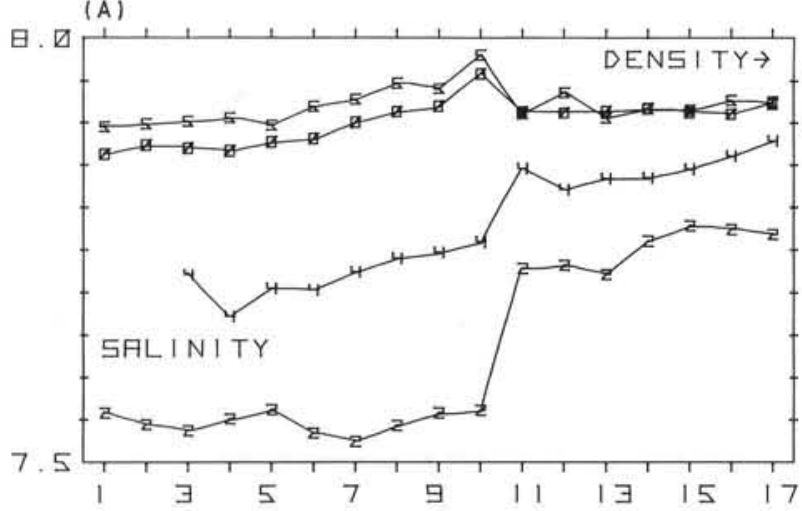

(B)

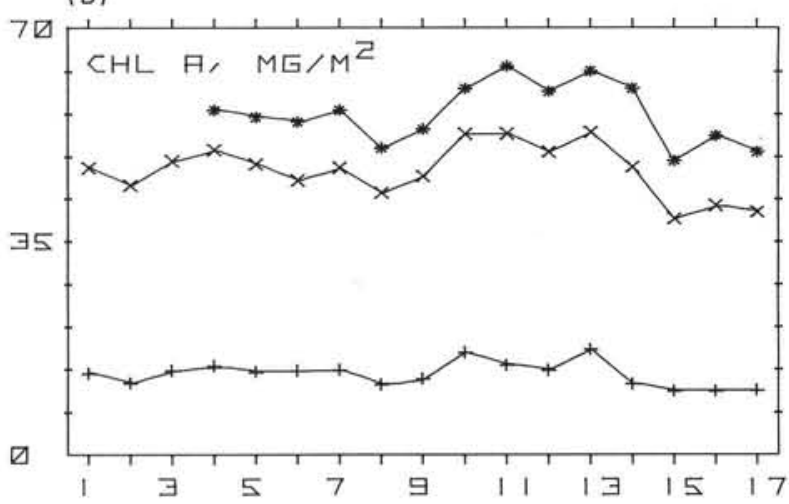

(C)

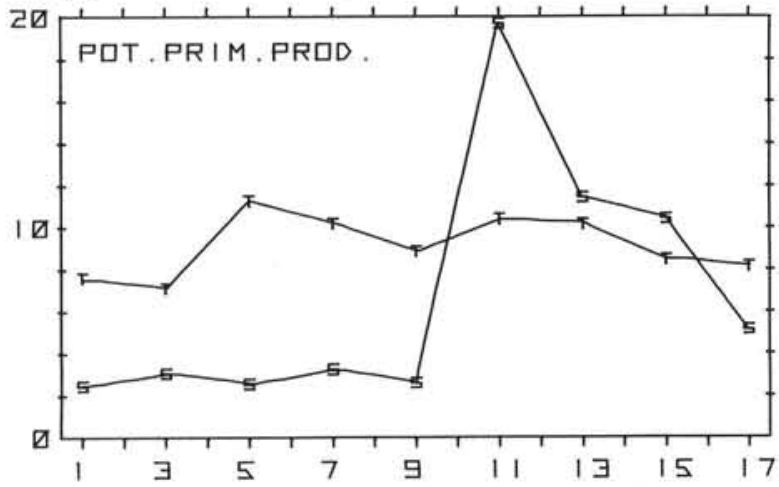

(D)

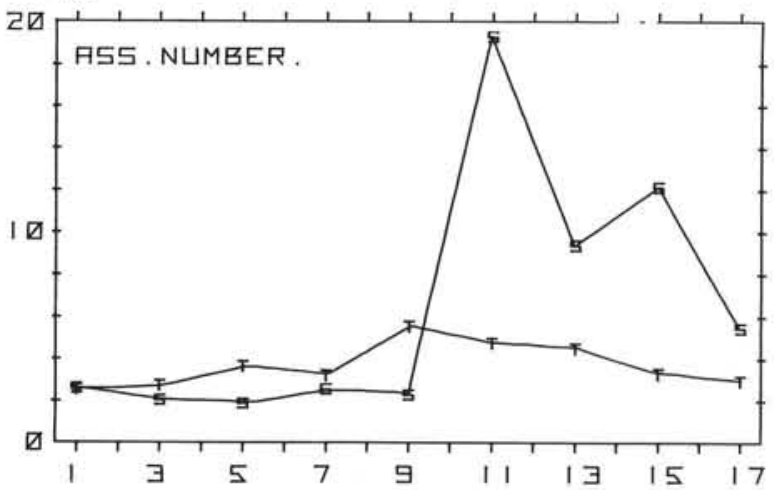

(E)

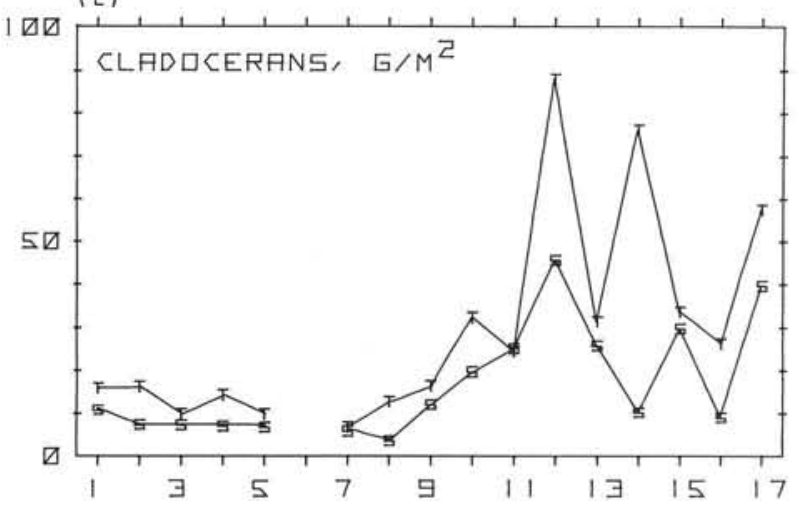

(F)

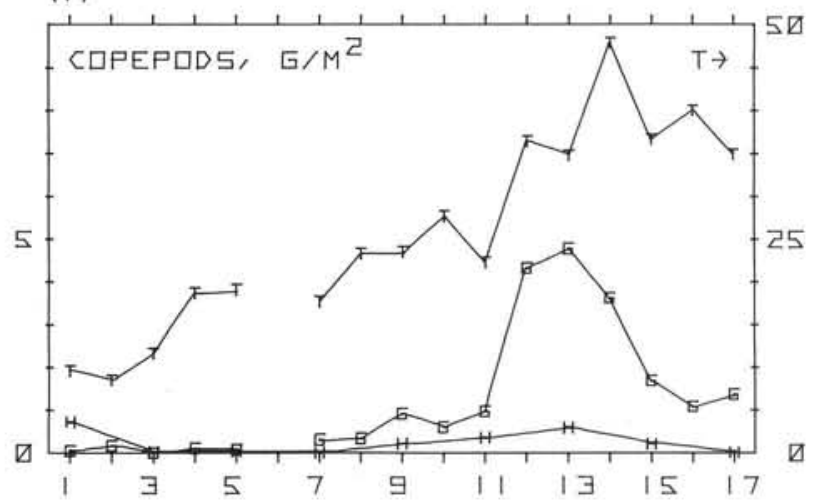

Fig. 6. Horizontal distributions along transect. (A) Near-surface density $\left(\sigma_{t}\right)$ at depths of $0.5 \mathrm{~m}(\varnothing)$ and $5 \mathrm{~m}(5)$, and salinity $(\%)$ at depths of $25 \mathrm{~m} \mathrm{(2)}$ and $40 \mathrm{~m} \mathrm{(4)} \mathrm{on} \mathrm{Section} \mathrm{G.} \mathrm{Notice} \mathrm{discontinuities} \mathrm{near} \mathrm{Station} \mathrm{10.} \mathrm{(B)} \mathrm{Vertically} \mathrm{integrated} \mathrm{chlorophyll} \mathrm{a}$ concentration between 0 to $10 \mathrm{~m}(+), 0$ to $30 \mathrm{~m}(\mathrm{x}), 0$ to $60 \mathrm{~m}\left({ }^{*}\right)$. Means for Sections $\mathrm{G}$ and $\mathrm{H}$. (C) Potential primary production

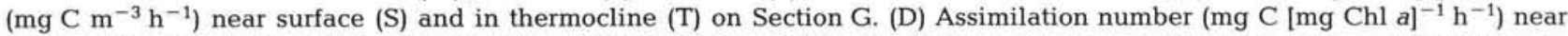
surface $(\mathrm{S})$ and in thermocline (T) on Section G. (E) Cladoceran biomass of total water column (T) and in surface, 10-m layer (S). Means for Sections G and H. (F) Copepod biomass in upper 10-m layer on Sections G (G) and H (H), and of total water column (T, mean for Sections $\mathrm{G}$ and $\mathrm{H}$ )

assimilation numbers (A. N.) were uniformly low in the low-salinity water (mean A. N. = 2.25). A striking 8fold increase in A. N. (to $19.3 \mathrm{mg} \mathrm{C}\left[\mathrm{mg} \mathrm{Chl} \mathrm{a}^{-1} \mathrm{~h}^{-1}\right.$ ) and a 7 -fold increase in potential primary production (to $19.7 \mathrm{mg} \mathrm{C} \mathrm{m}^{-3} \mathrm{~h}^{-1}$ ), occurred at G11, adjacent to the salinity front and the near-surface density feature at G10. While both the near-surface productivity and A. N. levelled down further away from the front, the average values were still 4 to 5 times higher on the higher-salinity side (Table 1). In the thermocline the pattern was not so striking, but a band of a recognizable maximum in A. N. (Fig. 6D) was again apparent near the front (St. 9 to 13). On the low-salinity side, the assimilation numbers were lower in the near-surface layer compared to the thermocline, whereas on the higher-salinity side the opposite was true. We may 
Table 1. Comparison of mean properties on either side of the salinity front. Either difference ('salty' - 'fresh') or ratio ('salty'/ 'fresh') is presented for the physical or biological variables, respectively

\begin{tabular}{|c|c|c|c|c|}
\hline $\begin{array}{l}\text { Variable } \\
\text { units }\end{array}$ & $\begin{array}{l}\text { Depth } \\
\text { (m) }\end{array}$ & $\begin{array}{l}\text { 'Fresh' mean } \\
\quad \pm \text { S.D. }\end{array}$ & $\begin{array}{l}\text { 'Salty' mean } \\
\quad \pm \text { S.D. }\end{array}$ & $\begin{array}{c}\text { Difference } \\
\text { or ratio }\end{array}$ \\
\hline Temperature & 0.5 & $21.76 \pm 0.41$ & $21.42 \pm 0.26$ & -0.34 \\
\hline \multirow[t]{2}{*}{${ }^{\circ} \mathrm{C}$} & 15 & $12.82 \pm 1.20$ & $14.23 \pm 1.30$ & 1.42 \\
\hline & 50 & $2.52 \pm 0.27$ & $3.01 \pm 0.17$ & 0.49 \\
\hline Salinity & 0.5 & $7.60 \pm 0.11$ & $7.77 \pm 0.02$ & 0.17 \\
\hline \multirow[t]{2}{*}{$\%$} & 15 & $7.46 \pm 0.04$ & $7.72 \pm 0.03$ & 0.26 \\
\hline & 50 & $7.84 \pm 0.04$ & $7.89 \pm 0.01$ & 0.06 \\
\hline Chlorophyll a & 0.5 & $0.98 \pm 0.21$ & $1.09 \pm 0.24$ & 1.11 \\
\hline \multirow[t]{2}{*}{$\mathrm{mg} \mathrm{m}^{-3}$} & 15 & $2.49 \pm 0.37$ & $2.24 \pm 0.47$ & 0.90 \\
\hline & 50 & $0.16 \pm 0.05$ & $0.30 \pm 0.07$ & 1.95 \\
\hline \multirow[t]{3}{*}{$\mathrm{mg} \mathrm{m}^{-2}$} & $0-30$ & $46.7 \pm 2.5$ & $46.0 \pm 7.7$ & 0.99 \\
\hline & $30-60$ & $8.2 \pm 1.3$ & $10.6 \pm 1.1$ & 1.29 \\
\hline & $0-60$ & $54.8 \pm 2.4$ & $56.6 \pm 8.2$ & 1.03 \\
\hline Pot. prim. prod. & 1 & $2.8 \pm 0.3$ & $11.7 \pm 6.0$ & 4.19 \\
\hline $\mathrm{mgC} \mathrm{m} \mathrm{m}^{-3} \mathrm{~h}^{-1}$ & $12-15$ & $9.0 \pm 1.7$ & $9.3 \pm 1.2$ & 1.03 \\
\hline Assim. number & 1 & $2.3 \pm 0.3$ & $11.6 \pm 5.9$ & 5.10 \\
\hline $\mathrm{mgC}(\mathrm{mgChla})^{-1} \mathrm{~h}^{-1}$ & $12-15$ & $3.5 \pm 1.2$ & $3.9 \pm 0.9$ & 1.09 \\
\hline Zooplankton $\mathrm{g} \mathrm{m}^{-2}$ & $0-70$ & $31.2 \pm 9.6$ & $79.2 \pm 33.1$ & 2.54 \\
\hline Cladocerans & $0-70$ & $12.1 \pm 4.6$ & $43.9 \pm 25.1$ & 3.64 \\
\hline Copepods & $0-70$ & $17.0 \pm 7.5$ & $34.7 \pm 11.0$ & 2.04 \\
\hline Rotifers & $0-70$ & $0.9 \pm 0.6$ & $0.4 \pm 0.4$ & 0.48 \\
\hline
\end{tabular}

conclude that the near-surface phytoplankton was nutrient-deficient in the low-salinity water, whereas in the higher-salinity water adjacent to the front, the phytoplankton was probably growing at near-maximum rates. The low-salinity wedge with the chlorophyll maximum in it probably contained a growing and healthy phytoplankton population, and was not merely an accumulation of non-growing, sunken cells. This can be seen from the relatively high A. N. in the thermocline (up to 5.54 at G9). It appears that the conditions for phytoplankton growth were more favourable near the surface on the higher-salinity side and in the thermocline on the lower-salinity side.

Although most of the primary productivity parameters are subject to diurnal variation (Gargas et al., 1979), no attempt was made to eliminate this source of variability. As the observed patterns were so obvious, a relatively minor diurnal variation could hardly bring about significant changes. As the stations with higher assimilation numbers were completed at night when A. N. should be in its minimum, consideration of the diurnal cycle could even further accentuate the observed pattern.

\section{Phytoplankton species composition}

Phytoplankton cell counts were too sparse (St. G1, G13, G17) to allow a proper analysis. Nevertheless, some inferences can be made. At G1, in the lowsalinity water, the whole water column was dominated by Cyanophyta ( 74 to $89 \%$ of the biomass), the dominant species being Nodularia spumigena near the surface and Microcystis aeruginosa in and below the thermocline. At G13, the nearest station to the front sampled, the dominance of the blue-greens was below $50 \%$ at all depths, excluding $35 \mathrm{~m}$. Chlorophyta and Pyrrophyta gained considerable importance (both up to $30 \%$ of the biomass). As the most significant feature, diatoms, being nearly absent elsewhere, made up nearly $20 \%$ of the biomass at $7 \mathrm{~m}$. At G17, the bluegreens increased again (to about $55 \%$ ), with Aphanizomenon flos-aqua as the dominant species. Chlorophyta and Pyrrophyta retained 15 to $20 \%$. These features are not inconsistent with the observations in other frontal regions (Holligan, 1981) thus confirming that diatoms tend to be most abundant in more mixed waters. The abundance of Chlorophyta is, of course, peculiar to the brackish Baltic Sea.

\section{Zooplankton}

The zooplankton community was similar in composition on both sides of the front. A total of 6 species of copepods, 3 species of cladocerans, and 3 species of rotifers was found. Cladocerans, mainly Bosmina coregoni maritima, made up approximately $90 \%$ of the upper 10-m zooplankton biomass and $50 \%$ of the total water column zooplankton biomass. Copepods, especially Pseudocalanus elongatus, were the second important group, forming an average $47 \%$ of the col- 
umn zooplankton biomass. The distributions and abundances of the zooplankton species showed high along-section and between-section variability (C.V. for the copepod, cladoceran, and rotifer column biomasses were, respectively, 49, 84, and $88 \%$ ). Despite the high sample variability, an obvious increase in both the cladoceran biomass and its variability was evident in the higher-salinity water (Fig. 6E). The increased sample variability may well be the result of an increased horizontal patchiness.

The column copepod biomass was increasing towards the higher-salinity side (Fig. 6F). The strong maximum of the upper 10-m copepod biomass was obviously caused by the diel vertical migration (ascending at night). However, the distributions on the backward section next morning as well as the column copepod biomass show quite similar patterns in spite of the different levels.

Owing to the high sample variability (low signal to noise ratio) no specific features could be proved for the frontal zone. However, the statistically insignificant maxima in the distributions of copepods and cladocerans were probably associated with the higher-salinity water adjacent to the front. On the average, the increase in the column zooplankton biomass in the higher-salinity water was 2 -fold in the case of copepods, and 3.6-fold in case of cladocerans (Table 1). By contrast, the rotifer biomass (mainly Synchaeta baltica and $S$. monopus) was at its maximum in the lowsalinity water (Table 1).

\section{DISCUSSION}

The Baltic Sea, owing to its shallow depths, irregular bottom topography, and complicated vertical stratification, displays a close coupling between physical and biological processes. The importance of interactions between the physical and biological subsystems for the Baltic ecology has been stressed by Jansson (1978). However, the important mechanisms which govern the transfer of nutrients into the surface layers are poorly understood. Spatial surveys of the meso-scale distribution of chlorophyll $a$ and hydrographic variables (Kahru et al., 1981, 1982) have shown a striking variability of the phytoplankton standing crop. If the upward transfer of nutrients is effected only during the winter convection, this variability can hardly be explained, as there should be enough time for the nutrients to be spread out evenly. Ojaveer and Kaleis (1974), Shaffer (1979), and Kahru (1982) have presented evidence that intense vertical mixing is localized on submarine banks, slopes, or special topography, where the halocline comes into contact with the ground. We have found evidence that the increased vertical transfer is also associated with the shoaling of the halocline (Kahru et al., 1982) and, particularly, with the narrowing of the intermediate layer between thermocline and halocline (Kahru et al., 1981). As the isopycnal depths are influenced by geostrophy, and the deeper currents are guided by topography, this means a more indirect influence of the bottom topography. Yet another mechanism, due to the interactions between the phytoplankton-nutrient dynamics and synoptic-scale internal undulations in the thermocline, was suggested as an additional source of the mesoscale patchiness (Kahru, 1983).

The sections described here were planned for a more detailed study of the coupling between the biological and the physical subsystems. In conditions of nearly a month of calm weather preceeding the observations we could not expect to find vigorous mixing (e.g. due to internal wave breaking), commonly associated with strong winds and changes in air pressure (Krauss, 1981). Instead, we were lucky to find one more conceivably important mechanism for the physical-biological coupling, i.e. the fronts. Observational and numerical studies of fronts (e.g. Tang, 1982) have shown that intense upwelling as well as mixing can take place in frontal zones.

Fronts in the Baltic have not yet received systematic study even from a purely hydrographic point of view. A single detailed hydrographic description of a front in the open Baltic (Aitsam et al., 1982b) suggests that the Baltic fronts can, indeed, be sites of abrupt current changes, interleavings, intrusions, strong current shears, and mixing. The Baltic fronts are probably less persistent and less stationary, compared to the wellstudied tidal fronts around Britain. However, due to the persistent influence of topography and general circulation, there may well be areas favourable for frontal generation and persistence. The biology of fronts is still an emerging field of studies. An understanding of the processes taking place in fronts is clearly needed for biological productivity models. Savidge (1976) discussed the stimulation of phytoplankton growth in fronts resulting from the nutrient enrichment by upwelling, mixing of complementary water masses, and the accumulation of buoyant material at zones of convergence. Contrary to the fronts in tidally active areas, the thermocline in the Baltic is hardly ever totally eroded in summer, and the frontal exchange processes are probably more delicate. Attempts to describe the biological structure of fronts are severely hampered by the difficulties of high-resolution biological sampling in dynamic physical environments. However, recent improvements in sampling techniques, e.g. high-resolution Batfish profiles of the distributions of temperature, salinity, chlorophyll, and zooplankton (Herman et al., 1981), are promising. To 


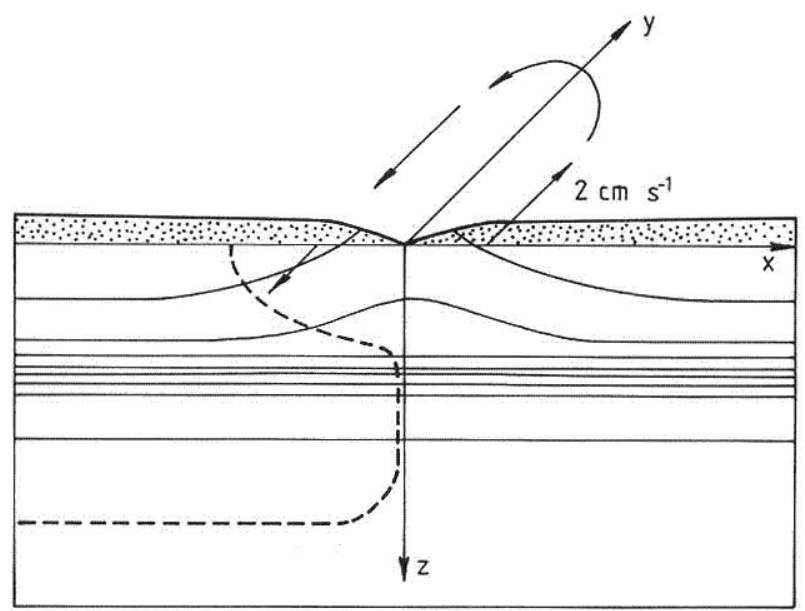

Fig. 7. Schematic explanation of proposed mechanism for frontal structure and upwelling. Dashed line: observed boundary between water masses with different salinities and lower-salinity water remaining to the upper left corner. Continuous lines: isopycnals (or isotherms); arrows: cyclonic circulation; stippled area: supposed deformation of free surface

the authors' knowledge, we have presented the first physical-biological description of a frontal structure in the open Baltic.

The front was primarily a salinity front and not so much a density front. Hence, the dynamic processes in the front were conceivably not so vigorous as in density fronts (see Aitsam et al., 1982b). The following scenario can be proposed to explain the observed frontal structure and the supposed frontal upwelling (Fig. 7). In conditions of negligible wind mixing, 2 water masses with different salinities drifted slowly towards one another. A region of convergence was produced in the frontal zone. Initially, the front was presumably vertical, coinciding with the $z$-axis in Fig. 7. Due to convergence, the layer above the thermocline was stretched vertically. Much more energy would have been needed to force down the isopycnals in the thermocline, where the maximal vertical density gradient existed, than to raise the near-surface isopycnals in a much weaker density gradient. Hence, upwelling was produced in the upper thermocline. At the same time, cyclonic circulation was established. A geostrophic estimate, based on actual density data, gives a value of $2 \mathrm{~cm} \mathrm{~s}^{-1}$ for this circulation. In this process the water with higher salinity overrode the low-salinity water at the surface (Fig. 3B). There is no doubt that, if a water mass with the same temperature but higher salinity overrides another water mass, hydrostatic instability is inevitable. Therefore, the observed pattern can be explained by evoking dynamics only, i.e. by the uplift of isotherms/isopycnals and the corresponding circulation. Of course, the proposed scenario is only tentative, but it agrees quite well with the observed data. The relatively moderate physical forcing was sufficient to the frontal zone. A broader and less significant band of increased chlorophyll standing crop and a considerable increase in the zooplankton standing stock on the high-salinity side of the front were observed. To understand the actual trophic structure, better horizontal and vertical resolution is needed for the zooplankton data. The relation between the vertical chlorophyll maximum and zooplankton distribution has not been studied in the Baltic. Owing to the more than doubled zooplankton standing stock on the high-salinity side of the front, the nutrient cycling there had to be faster, since the phytoplankton biomass (if that is what chlorophyll a values represent) did not increase to the same extent. This corresponds well with the increased primary productivity on the high-salinity side.

Hence, the fronts represent one more example of the close coupling between physical and biological subsystems in the Baltic. Biological implications of fronts in the Baltic are strongly dependent on the frequency and persistency of fronts. If the fronts tend to persist over a time-scale of days, rather than weeks, the implications of fronts may be as important but their study becomes more difficult. These are still a matter of speculation, but the extended use of satellite information together with concurrent in situ studies should bring about a break-through in the future.

Acknowledgements. We thank Anne Kahru for help in the photometric chlorophyll determinations and Aime Randveer for the phytoplankton microscopic analysis. We also thank $\mathrm{J}$. Lokk, the chief scientist of the cruise, for his support.

\section{LITERATURE CITED}

Aitsam, A., Elken, J., Kahru, M., Laanemets, J., Pajuste, M. Pevelson, J. (1982a). Some results of a joint physical/ chemical experiment in the Gotland Basin in June 1981 by R/V 'Ayu-Dag' and R/V 'Poseidon'. Proceedings of XIII Conference of Baltic Oceanographers, Vol. 1. Valtion Painatuskeskus, Helsinki, p. 47-69

Aitsam, A., Elken, J., Talpsepp, L., Laanemets, J. (1983). Topographically induced variability in the Baltic Sea. In: Gade, G. H., Edwards, A., Svendsen, H. (ed.) Coastal oceanography. NATO Conference Series IV, Marine Sciences, Vol. 11. Plenum Press, New York, p. 253-270

Aitsam, A., Pavelson, J., Laanemets, J., Lilover, M.-J. (1982b). Preliminary analysis of a front in the Baltic Sea. Proceedings of XIII Conference of Baltic Oceanographers, Vol. 1. Valtion Painatuskeskus, Helsinki, p. 70-86

Bowman, M. J., Esaias, W. E. (ed.) (1978). Oceanic fronts in coastal processes. Springer-Verlag, Berlin

Edler, L. (ed.) (1979). Recommendations for marine biological studies in the Baltic Sea. Baltic Marine Biologists Publication, No. 5

Floodgate, G. D., Fogg, G. E., Jones, D. A., Lochte, K., Turley, C. M. (1981). Microbiological and zooplankton activity at a front in Liverpool Bay. Nature, Lond. 290: 133-136 
Gargas, E. (1975). A manual for phytoplankton primary production studies in the Baltic. Baltic Marine Biologists Publication No. 2

Gargas, E., Hare, I., Martens, P., Edler, L. (1979). Diel changes in phytoplankton photosynthetic efficiency in brackish waters. Mar. Biol. 52: 113-122

Herman, A. W., Sameoto, D. D., Longhurst, A. R. (1981). Vertical and horizontal distribution patterns of copepods near the shelf break south of Nova Scotia. Can. J. Fish. aquat. Sci. 38: 1065-1076

Holligan, P. M. (1981). Biological implications of fronts on the northwest European continental shelf. Phil. Trans. R. Soc. Lond. A302: 547-562

Horstmann, U. (1983). Distribution patterns of temperature and water colour in the Baltic Sea as recorded in satellite images: indicators for phytoplankton growth. Ber. Inst. Meeresk. Univ. Kiel 106 (1)

Højerslev, N. K. (1982). Bio-optical properties of the Fladen Ground: 'Meteor' - FLEX-75 and FLEX-76. J. Cons. int. Explor. Mer 40: 272-290

Jansson, B.-O. (1978). The Baltic - a system analysis of a semienclosed sea. In: Charnock, H., Deacon, G. (ed.) Advances in oceanography. Plenum Press, New York, p. 131-183

Kahru, M. (1982). The influence of hydrodynamics on the chlorophyll field in the open Baltic. In: Nihoul, J. C. J. (ed.) Hydrodynamics of semi-enclosed seas. Elsevier, Amsterdam, p. 531-542

Kahru, M. (1983). Phytoplankton patchiness generated by long internal waves: a model. Mar. Ecol. Prog. Ser. 10: 111-117
Kahru, M., Aitsam, A. (1984). Chlorophyll variability in the sea: a pitfall for monitoring. Submitted to J. Cons. int. Explor. Mer

Kahru, M., Aitsam, A., Elken, J. (1981). Coarse-scale spatial structure of phytoplankton standing crop in relation to hydrography in the open Baltic Sea. Mar. Ecol. Prog. Ser. 5: $311-318$

Kahru, M., Aitsam, A., Elken, J. (1982). Spatio-temporal dynamics of chlorophyll in the open Baltic Sea. J. Plankton Res. 4: 779-790

Krauss, W. (1981). The erosion of a thermocline. J. phys. Oceanogr. 11: 415-433

Ojaveer, E. A., Kaleis, M. V. (1974). On some oceanographic factors determining the abundance and distribution of pelagic fish in the Baltic Sea. Oceanology 14: 544-554

Pingree, R. D., Mardell, G. T., Holligan, P. M., Griffiths, D. K., Smithers, J. (1982). Celtic Sea and Armorican current structure and the vertical distributions of temperature and chlorophyll. Continental Shelf Res. 1: 99-116

Savidge, G. (1976). A preliminary study of the distribution of chlorophyll $a$ in the vicinity of fronts in the Celtic and western Irish seas. Estuar. coast. mar. Sci. 4: 617-625

Shaffer, G. (1979). On the phosphorus and oxygen dynamics of the Baltic Sea. Contr. Askö Lab. Univ. Stockholm, No. 26

Simpson, J. H., Hunter, J. R. (1974). Fronts in the Irish Sea. Nature, Lond. 250: 404-406

Tang, C. L. (1982). A model for frontal upwelling. In: Nihoul, J. C. J. (ed.) Hydrodynamics of semi-enclosed seas. Elsevier, Amsterdam, p. 329-348 